\title{
Detection of Degradation in Polyester Implants by Analysing Mode Shapes of Structure Vibration
}

\author{
Hassan Samami and Jingzhe Pan* \\ Department of Engineering, University of Leicester, Leicester, UK \\ * Corresponding author, jp165@le.ac.uk, tel. 44 (0) 116223 1092, fax 44 (0) 1162522525
}

\begin{abstract}
This paper presents a numerical study on using vibration analysis to detect degradation in degrading polymesters. A numerical model of a degrading plate sample is considered. The plate is assumed to degrade following the typical behaviour of amorphous copolymers of polylactide and polyglycolide. Due to the well-known autocatalytic effect in the degradation of these polyesters, the inner core of the plate degrades faster than outer surface region, forming layers of materials with varying Young's modulus. Firstly the change in molecular weight and corresponding change in Young's modulus at different times are calculated using the mathematical models developed in our previous work. Secondly the first four mode shapes of transverse vibration of the plate are calculated using the finite element method. Finally the curvature of the mode shapes are calculated and related to the spatial distribution of the polymer degradation. It is shown that the curvature of the mode shapes can be used to detect the onset and distribution of polymer degradation. The level of measurement accuracy required in an experiment is presented to guide practical applications of the method. At the end of this paper a demonstration case of coronary stent is presented showing how the method can be used to detect degradation in an implant of sophisticated structure.
\end{abstract}

Key words: polymer degradation; detection; biodegradable polymers; dynamic analysis; mode shape 


\section{Introduction}

A bioresorbable polyester degrades in the presence of water due to hydrolysis reactions between water molecules and ester bonds of the polymer chains. The molecular weight of the polymer reduces with time because of the polymer chain scissions which lead to the change in its physical properties, such as Young's modulus. Furthermore typical bioresorbable polymers for medical implants, such as polylactide (PLA), polyglycolide (PGA) and their copolymers, degrade heterogeneously. This is because the hydrolysis reaction of these polymers is autocatalytic. The hydrolysis reaction produces acid and alcohol end groups. The carboxylic acid end groups have a high degree of dissociation and give rise to an acidic environment, which significantly accelerates the hydrolysis rate. Near the surface of a device, the acid end groups of short chains can diffuse into the surrounding environment retarding the acceleration. At the core of a device the short chains cannot leave quickly and therefore causes acid accumulation leading to a fast degradation. Consequently both the average molecular weight and Young's modulus in the surface region are higher than those at the core of an implant. It is important to understand and control this non-uniform degradation in the design and optimisation of these medical devices. However medical implants such as coronary stents are typically very small in size and it is difficult to measure the spatial variation of the polymer degradation using standard experimental techniques familiar to polymer chemists. The purpose of this paper is to present an alternative method to detect the spatial distribution of the degradation using analysis of dynamic responses of a degrading implant.

The vibration at any location of a structure can be monitored by using an accelerometer or similar transducers to yield a dynamic response spectrum and modal parameters such as frequencies, mode shapes and damping. The basic idea behind detecting, locating and characterizing damage in structural and mechanical systems using measured vibration response is that changes in the physical properties of the structure will cause detectable changes in the modal properties because modal properties are functions of the physical properties (Doebling et al.). Numerous studies have investigated the effect of a crack or local defect on the dynamic behaviour which were reviewed by (Dimarogonas, 1996). Many methods have been studied using the vibration analysis for damage detection. For example, the damage can be detected using shifts in resonant frequencies of a damaged structure, which was revised by Salawu and Doebling (Doebling et al., 1996, Salawu, 1997). However it is well known that the changes in frequency caused by damage are usually very small and 
cannot be used to locate the exact location of the damage. Alternatively the mode shapes and in particular their derivatives are more sensitive to local damages (Yuen, 1985). Pandey et al (Pandey et al., 1991) showed that the curvature (second derivative) of the modal mode shapes are highly sensitive to damage and can be used to localize them. For a beam, the curvatures of a mode shape are related to the local flexural stiffness. The change in the curvature increases with the reduction in the local flexibility which corresponds to local damage in a structure. The amount of damage can be obtained from the magnitude of the change in curvature. Effective algorithms to locate damages using curvatures of the mode shapes have been developed (Fan and Qiao, 2011).

The finite element method used discrete elements to represent a structure and found its mode shapes by solving an eigen value problem numerically. The method has been widely used to solve various problems in biomedical engineering and has played a significant role in improving the coronary stent design in recent years. Some typical examples of applying the finite element analysis in biomdecal engineering can be found in the works by AURICCHIO et al., 2001, De Beule et al., 2005, Etave et al., 2001, Gu et al., 2005, Imani et al., 2013, Lally et al., 2005, Lee et al., 2015, Migliavacca et al., 2002, Narracott et al., 2007, Wang et $a l ., 2006$. In this paper a finite element model of a plate sample is considered. The sample is assumed to degrade following the behaviour of typical amorphous polyesters such as PLA, PGA and their copolymers. However the numerical study is only loosely based on these polymers in the sense that any small change in the polymer details such as molecular weight of the polymer unit will not change the conclusions. Firstly the change in molecular weight and corresponding change in Young's modulus at different times of degradation are calculated using the mathematical models developed by Pan and Samami (Samami and Pan, 2016). Secondly the first four displacement mode shapes of transverse vibration of the plate are calculated using the finite element method. Finally the curvature of the mode shapes are calculated and related to the spatial distribution of the polymer degradation. It is shown that the curvature of the mode shapes can be used to effectively detect the distribution of polymer degradation. The level of measurement accuracy that is required in an experiment is also presented to guide practical applications of the method. At the end of this paper a demonstration case of coronary stent is presented showing how the method can be used to detect degradation in an implant of sophisticated structure.

\section{Calculation of distributions of molecular weight and Young's modulus}


A simple rectangular plate as shown in Fig. 1 is taken here as the example of study because such plates are often used in degradation experiments. Pan and co-workers (Pan, 2014) developed a mathematical model for the degradation of bioresorbable polymers. Han and Pan (Han and Pan, 2013) presented a series of case studies of using a commercial finite element package, COMSOL Multiphysics, to obtain the molecular weight distributions in degrading implants. Here their model is used to obtain the distributions of molecular weight in the plate shown in Fig. 1. Details of the degradation model can be found in (Pan, 2014) and (Han and Pan, 2013). Table 1 provided the model parameters which are used in the calculation for molecular weight distributions using COMSOL Multiphysics. These parameters were taken from the model used by Han and Pan (Han and Pan, 2013) for fitting the degradation data of a PLA/PGA copolymer obtained by Grizzi et al. It should be emphasised that the data used in the numerical examples here are only loosely based on the mentioned polymers. Use of slightly different values of these data, such as different molecular weight of a polymer unit, do not affect the conclusions of this numerical study. They only change the numerical output. It is also worth to point out that a very large value was used for the diffusion coefficient of the short chains. This is because the bulk degradation process of polyesters is often accompanied by some extent of short chain erosion and formation of microscopic channels which are reflected in the model by using a large effective diffusion coefficient. In the analysis it is assumed that the left end of the plate is sealed from diffusion of short polymer chains while all the other surfaces act as perfect sink for the short chain diffusion (zero concentration). It is also assumed that there are no residual monomers in the polymer at the beginning of the degradation.

Fig. 2 shows the calculated distribution of molecular weight of the plate after 12 weeks of degradation. A total number of 25740 three dimensional quadratic hexahedral elements were used in the analysis to ensure convergence. The different grey scales indicate that the edges of the plate degrade slightly slower than the flat surfaces because these edges are exposed to water on both sides.

As the molecular weight decreases, the Young's modulus of the polymer decreases correspondingly. Samami and Pan (Samami and Pan, 2016) presented an analytical constitutive law for degrading polymers using which Young's modulus can be calculated for any given molecular weight. In this paper, their constitutive law is used to calculate the distribution of Young's Modulus in the plate. The constitutive law requires three input data: 
the initial Young's modulus and Poisson's ratio, which are taken as $E_{0}=10 \mathrm{GPA}$ and $v=0.35$ in this study, and the effective size of the cavity generated by each polymer chain scission, which is taken as $\mathrm{r}=0.9 \mathrm{~nm}$. These data were used by Samami and Pan (Samami and Pan, 2016)to fit the experimental data for amorphous film made of poly(DL-lactide) (PDLLA) obtained by Tsuji et al (Tsuji, 2002). Fig. 3 shows the calculated distributions of Young's modulus in the plate after 3, 6, 9 and 12 weeks of degradation along paths $A-B$, $C-D$ and $E-F$ which are indicated in Fig. 2. It can be observed from Fig. 3 that the Young's modulus is significantly higher in a small region near the free surfaces of the plate than the core and that the plate is almost fully degraded after 12 weeks.

\section{Dynamic analysis of mode shapes and their curvatures}

Using a finite element discretisation, the mode shapes of a structure can be found by solving the following eigenvalue problem:

$$
[K]\left[U^{(n)}\right]=\omega_{n}^{2}[M]\left[U^{(n)}\right]
$$

where $[K],[M]$ and $\left[U^{(n)}\right]$ represent the stiffness matrix, mass matrix and eigenvector, i.e. the mode shape, respectively. $\omega_{n}$ represents the $n$-th natural circular frequency of the structure. For problems of small deformation, the curvature of the mode shape can simply be calculated using a finite difference scheme using

$U^{\prime \prime(n)}=\frac{\partial^{2} U^{(n)}}{\partial x^{2}}$

where $x$ represents the coordinate along the analysis path. The absolute difference between the curvatures of a degrading structure and its intact counterpart can be used to detect degradation:

$$
\Delta U^{\prime \prime(n)}=\left|U_{\text {intact }}^{\prime \prime(n)}-U_{\text {degrading }}^{\prime \prime}\right|
$$

In the dynamic analysis, the left end of the plate shown Fig 1 is completely fixed. The plate then behaves as a cantilever beam. Both two and three dimensional finite elements were used in the finite element model for the dynamic analysis and the first four mode shapes of the bending displacement were examined. Again COMSOL Multiphysics is used in this study.

\subsection{Two dimensional (plane stress) analysis}


Inspired by observing the distributions of Young's modulus shown in Fig. 3, the plate is divided into a core region which is assigned a value of $\mathrm{E}$ that does not vary with position and 9 layers near the surface region, each of which is assigned a different value of $E$ as calculated in section 2. Each one of the 9 surface layers have a thickness of $5.7582 \times 10^{-5} \mathrm{~m}$ and $5.6179 \times 10^{-5} \mathrm{~m}$ in the $x$ and $z$ directions respectively. The size of the core region was $0.02896 \mathrm{~m}$ and $3.988 \times 10^{-3} \mathrm{~m}$ in the $x$ and $z$ directions respectively. Figure 4 shows the layered model used in the dynamic analysis. A total numbers of 2605 and 445 quadratic quadrilateral elements were used in directions $x$ and $z$ respectively which ensure 5 elements across the thickness of each layer. Figure 5 shows a zoomed-in region of the finite element mesh.

Fig. 6 shows the first four bending mode shapes of the cantilever beam. Each sub-figure represents one mode shape at different degradation times $(0,3,6,9$ and 12 weeks). It can be observed from these figures that the mode shapes of the intact and degrading beams are almost identical which means that the mode shapes themselves cannot provide any useful information on polymer degradation.

Fig. 7 shows the curvatures of the first four mode shapes of the 2D beam. Each sub-figure represents the curvatures of one mode shape at different degradation times $(0,3,6,9$ and 12 weeks). It can be seen that the curvatures, particularly those of the higher mode shapes indicate the locations where the change in Young's modulus occur, i.e. both ends of the plate. The amplitude of the change in the curvatures increases as degradation proceeds, which can be used to quantify the level of degradation in these regions.

It turns out that polymer degradation can be better revealed by comparing the curvatures of mode shapes of intact and degraded polymers. Fig 8 shows the absolute difference between the curvatures of mode shape, ( $\Delta U^{n(n)}$ of Eqn. 3), calculated at different degradation times. It can be observed from this figure that the $\Delta U^{\prime \prime}$ changes dramatically at the left end of the beam, indicating the change in Young's modulus and hence the average molecular weight there. The figure also shows that the amplitude of $\Delta U^{\prime \prime}$ increases as degradation proceeds. The absolute difference in curvatures takes large values at the left end of the beam, almost zero along the core of the beam, and some small values at the free end. It therefore provides a good measure for the distribution of degradation. These numerical results suggest a potential experimental technique to detect degradation near the surface region. A cantilever beam can 
be made out of a sample using the surface region as its fixed end. By measuring the mode shape experimentally, Eqn (3) can then be used to detect polymer degradation.

The total thickness of the skin layer in the $x$ direction in the $2 \mathrm{D}$ model was set as $5.182 \times 10^{-4} \mathrm{~m}$. Fig. 9 shows that the values of the curvature difference correspond to the size of the surface skin layer.

\subsection{Three dimensional model}

In order to show that the conclusion obtained above is valid when the three dimensional effects in both polymer degradation and dynamic behaviour are considered, a full 3D dynamic model is developed. The model is shown in Fig 10 (zoomed-in).

The thicknesses of each 9 surface layers were taken as $2.8846 \times 10^{-4}, 0.8 \times 10^{-4}$ and $2.5 \times 10^{-4} \mathrm{~m}$ in the $x, \mathrm{y}$ and $z$ directions respectively, and the size of the core region was taken as $0.02481 \mathrm{~m}, 5.6 \times 10^{-4}$ and $5 \times 10^{-4} \mathrm{~m}$ in the $x, y$ and $z$ respectively. A total numbers of 104, 25 and 20 quadratic hexahedral elements in directions $x, y$ and $z$ respectively to ensure one element was used across the thickness of each layer.

Again the numerical results show that the mode shapes themselves do not provide any useful information for the degradation, which are therefore not presented here. Fig 11 shows the absolute difference between the curvatures of the fouth mode shapes, $\Delta U^{\prime \prime(4)}$, for the degrading and intact beams. It can be observed that the $\Delta U^{\prime \prime(4)}$ takes large values at the left end of the beam, almost zero along the core of the beam, and some small values at the free end. $\Delta U^{\prime \prime(4)}$ therefore provides a good measure for the distribution of degradation in the beam entirely consistent with the two dimensional analysis.

The total thickness of the skin layer in the $x$ direction in the $3 \mathrm{D}$ model was set as $2.596 \times 10^{-3} \mathrm{~m}$. Fig. 11 shows that the values of the curvature difference correspond to the locations of the surface layer and is almost exactly in consistence with the $3 \mathrm{D}$ model.

\subsection{The level of accuracy required for the mode shape measurement}

Because the mode shapes of the intact and degrading beams are very similar, the experimental measurement must be able to capture the small differences in the mode shapes 
between the intact and degraded beams. Consequently a high level of accuracy of measurement is required in order to calculate the curvature values accurately. Table 2 shows

the maximum values of $\left|\left(U_{\text {degrading }}^{(4)} / U_{\text {Non-degrading }}^{(4)}\right)-1\right|$ obtained in the $2 \mathrm{D}$ model at different degradation times. These values occur in the region between $x_{1}=1.12 \times 10^{-4}$ to $x_{2}=0.0024$ at the fixed end and between $x_{3}=0.0276$ to $x_{4}=0.03$ at the free end. The table shows that if one wishes to use the method to detect degradation at, for example, the end of week 3 then the mode shapes have to be measured to the accuracy of more than $0.27 \%$.

\section{A case study of coronary stent}

Biodegradable coronary stents are currently being used in several countries to restore blood flow for heart patients by opening a narrowed artery and providing support while the opened area heals (Butany et al., 2005, Gomez-Lara et al., 2010, Lobodzinski, 2008, Mani et al., 2007, O'Brien and Carroll, 2009, Ormiston and Serruys, 2009, Yang et al., 2013). It is important to understand their degradation behaviour in order to optimise the design of the next generation stents.

Fig. 12 shows a stent used in this case study. Because of symmetry, only the part shown the lower part of the figure was used in the analysis. The same material parameters and assumptions as in section 3 are used in the model to calculate the distribution of molecular weight and corresponding Young's modulus in the stent. Again the data used in this numerical study are only loosely based on the actual polymers. Use of slightly different values in these data do not change the conclusions. The data in Table 1 are used in this case study for the sake of consistency.

Fig 13 shows the calculated distribution of Young's modulus along path $A-B$ (shown in Fig 12) of the stent after 60 and 125 weeks of degradation respectively. It can be observed that the Young's modulus takes its lowest values at the junctions where degradation occurs fastest because of local acid accumulation. The locally accelerated degradation would lead to the breakup of the stent and hence needs to be detected and controlled. Fig 14 shows the first four mode shapes of bending displacement after 125 weeks of degradation obtained using the finite element analysis. As in the case of the plate, it is not possible to detect degradation from these mode shapes directly. Fig 15 shows the absolute difference between curvatures of mode shapes $\Delta U^{\prime \prime(n)}$ for the intact and degrading stent after 60 and125 weeks of degradation 
respectively. It can be observed from the figure that the junctions where degradation occurs fast are revealed by the peaks in the distribution of $\Delta U^{\prime \prime(n)}$ along the path A-B. These peaks are highlighted in the figure.

Two further observations can be made from Fig. 15. The first observation is that the fast degradation of the junctions is best detected by analysing the first model shape. The highlighted peaks in the figures are most clearly shown on the difference in curvatures between the first mode shapes of the degraded and intact stents. The second observation is that the degree of degradation can be measured by the amplitudes of these peaks. It can be observed that the values of $\Delta U^{\prime \prime(n)}$ at the junctions are significantly larger at 125 weeks (Fig. 15a) than those at 60 weeks. It is however difficult to directly relate the peak values back to the precise value of the molecular weight or Young's modulus at the junctions. The numerical study suggests a qualitative way to detect local degradation that would otherwise requires breaking up the stent and hence terminate the degradation test. A quantitative analysis of the degradation would require a fully reverse analysis of the dynamic data.

\section{Conclusion}

The numerical study presented in this paper shows that it is possible to detect distribution of molecular weight and Young's modulus in degrading implants by measuring their mode shapes of vibration. The mode shapes cannot be directly used because their differences between intact and degraded implants are very small. However by comparing the curvatures of the mode shapes between intact and degraded implants, locations where degradation rate varies can be clearly revealed. The accuracy of measurement that is required in such an experimental technique is also presented. As an example, it is shown that if one wishes to detect the degradation distribution at the end of week 3 for a plate sample, the mode shapes have to be measured to the accuracy of much higher than $0.27 \%$.

Acknowledgement: Samami gratefully acknowledges a partial $\mathrm{PhD}$ studentship from the University of Leicester which supported this work. All the finite element analysises presented in the paper were performed using COMSOL Multiphysics with license number 7074366. 


\section{References}

AURICCHIO, F., DI LORETO, M. \& SACCO, E. 2001. Finite-element analysis of a stenotic artery revascularization through a stent insertion. Computer Methods in Biomechanics and Biomedical Engineering, 4, 249-263.

BUTANY, J., CARMICHAEL, K., LEONG, S. \& COLLINS, M. 2005. Coronary artery stents: identification and evaluation. Journal of clinical pathology, 58, 795-804.

DE BEUlE, M., VAN IMPE, R., VERHEGGHE, B., SEGERS, P. \& VERDONCK, P. 2005. Finite element analysis and stent design: Reduction of dogboning. Technology and health care: official journal of the European Society for Engineering and Medicine, 14, 233-241.

DIMAROGONAS, A. D. 1996. Vibration of cracked structures: A state of the art review. Engineering Fracture Mechanics, 55, 831-857.

DOEBLING, S. W., FARRAR, C. R. \& PRIME, M. B. A summary review of vibrationbased damage identification methods.

DOEBLING, S. W., FARRAR, C. R., PRIME, M. B. \& SHEVITZ, D. W. 1996. Damage identification and health monitoring of structural and mechanical systems from changes in their vibration characteristics: a literature review. Los Alamos National Lab., NM (United States).

ETAVE, F., FINET, G., BOIVIN, M., BOYER, J.-C., RIOUFOL, G. \& THOLLET, G. 2001. Mechanical properties of coronary stents determined by using finite element analysis. Journal of Biomechanics, 34, 1065-1075.

FAN, W. \& QIAO, P. 2011. Vibration-based damage identification methods: a review and comparative study. Structural Health Monitoring, 10, 83-111.

GOMEZ-LARA, J., GARCIA-GARCIA, H. M., ONUMA, Y., GARG, S., REGAR, E., DE BRUYNE, B., WINDECKER, S., MCCLEAN, D., THUESEN, L. \& DUDEK, D. 2010. A comparison of the conformability of everolimus-eluting bioresorbable vascular scaffolds to metal platform coronary stents. JACC: Cardiovascular Interventions, 3, 1190-1198. 
GU, L., SANTRA, S., MERICLE, R. A. \& KUMAR, A. V. 2005. Finite element analysis of covered microstents. Journal of Biomechanics, 38, 1221-1227.

HAN, X. \& PAN, J. 2013. Finite element analysis of degradation of biodegradable medical devices. Medical Biotechnology, 01, 2(3):22.

IMANI, M., GOUDARZI, A. M., GANJI, D. D. \& AGHILI, A. L. 2013. The comprehensive finite element model for stenting: The influence of stent design on the outcome after coronary stent placement. Journal of Theoretical and Applied Mechanics, 51, 639-648.

LALLY, C., DOLAN, F. \& PRENDERGAST, P. J. 2005. Cardiovascular stent design and vessel stresses: a finite element analysis. Journal of Biomechanics, 38, 15741581.

LEE, J.-S., LEE, D. C., HA, D.-H., KIM, S. W. \& CHO, D.-W. 2015. Correction: Redefining the Septal L-Strut in Septal Surgery. PloS one, 10.

LOBODZINSKI, S. S. 2008. Bioabsorbable coronary stents. Cardiology journal, 15, $569-571$.

MANI, G., FELDMAN, M. D., PATEL, D. \& AGRAWAL, C. M. 2007. Coronary stents: A materials perspective. Biomaterials, 28, 1689-1710.

MIGLIAVACCA, F., PETRINI, L., COLOMBO, M., AURICCHIO, F. \& PIETRABISSA, R. 2002. Mechanical behavior of coronary stents investigated through the finite element method. Journal of Biomechanics, 35, 803-811.

NARRACOTT, A. J., LAWFORD, P. V., GUNN, J. P. \& HOSE, D. R. Balloon folding affects the symmetry of stent deployment: experimental and computational evidence. Engineering in Medicine and Biology Society, 2007. EMBS 2007. 29th Annual International Conference of the IEEE, 2007. IEEE, 3069-3073.

O'BRIEN, B. \& CARROLL, W. 2009. The evolution of cardiovascular stent materials and surfaces in response to clinical drivers: a review. Acta biomaterialia, 5, 945-958.

ORMISTON, J. A. \& SERRUYS, P. W. 2009. Bioabsorbable coronary stents. Circulation: Cardiovascular Interventions, 2, 255-260. 
PAN, J. 2014. Modelling degradation of bioresorbable polymeric medical devices, Elsevier.

PANDEY, A. K., BISWAS, M. \& SAMMAN, M. M. 1991. Damage detection from changes in curvature mode shapes. Journal of Sound and Vibration, 145, 321-332.

SALAWU, O. 1997. Detection of structural damage through changes in frequency: a review. Engineering Structures, 19, 718-723.

SAMAMI, H. \& PAN, J. 2016. A constitutive law for degrading bioresorbable polymers. Journal of the Mechanical Behavior of Biomedical Materials, 59, 430-445.

TSUJI, H. 2002. Autocatalytic hydrolysis of amorphous-made polylactides: effects of 1lactide content, tacticity, and enantiomeric polymer blending. Polymer, 43, 17891796.

WANG, W.-Q., LIANG, D.-K., YANG, D.-Z. \& QI, M. 2006. Analysis of the transient expansion behavior and design optimization of coronary stents by finite element method. Journal of Biomechanics, 39, 21-32.

YANG, A. S., JOW, K., MORRISON, A. D. \& LIMON, T. A. 2013. Polymeric stent. Google Patents.

YUEN, M. M. 1985. A numerical study of the eigenparameters of a damaged cantilever. Journal of Sound and Vibration, 103, 301-310. 
Table 1. Parameters used to calculate the molecular weight distribution

\begin{tabular}{|c|c|c|c|}
\hline Symbol & Value & Units & Description \\
\hline$k_{1}$ & $1.4 \mathrm{E}-4$ & $m o l m^{-3}$ & Non-catalytic hydrolysis rate constant \\
\hline$k_{2}$ & 0.0019 & $\mathrm{molm}^{-3}$ & Auto-catalytic scission rate constant \\
\hline$D_{\text {polymer }}$ & $8 \mathrm{E}-7$ & $m^{2}$ week $^{-1}$ & Diffusion coefficient of short chains in amorphous polymer \\
\hline$D_{\text {pore }}$ & $8 \mathrm{E}-4$ & $m^{2}$ week $^{-1}$ & Diffusion coefficient of short chains in liquid-filled pores \\
\hline$\alpha$ & 28 & - & \multirow{2}{*}{ Empirical parameters for oligomer production } \\
\hline$\beta$ & 2 & - & \\
\hline$M_{0}$ & 72 & $\mathrm{gmol}^{-1}$ & Molar mass \\
\hline$\rho$ & $1.25 \mathrm{E}-6$ & $g m^{3}$ & Density of PDLLA polymer \\
\hline$M_{n 0}$ & 34000 & $g m o l^{-1}$ & Initial number average molecular weight \\
\hline$C_{e 0}$ & 17300 & $\mathrm{~mol} \mathrm{~m}^{-3}$ & Initial number of ester units per unit volume \\
\hline$m$ & 4 & - & Degree of polymerization of the oligomers \\
\hline$n$ & 0.5 & - & Exponent for acid dissociation of - $\mathrm{COOH}$ end groups \\
\hline$N_{a d p 0}$ & 472.22 & $\mathrm{~mol} \mathrm{~m} \mathrm{~m}^{-3}$ & Average number of ester units per polymer chain \\
\hline$C_{o l 0}$ & 0 & mol m${ }^{-3}$ & Initial number of ester units of short chains per unit volume \\
\hline
\end{tabular}

Table2: The level of accuracy required for the mode shape measurement

\begin{tabular}{l|c|ccccc}
\hline \multicolumn{2}{l}{} & \multicolumn{5}{c}{$\left|\left(U_{\text {degrading }}^{(4)} / U_{\text {Non-degrading }}^{(4)}\right)-1\right|$} \\
\hline \multicolumn{2}{l}{ Degradation time } & $20 \mathrm{~h}$ & $3 \mathrm{~W}$ & $6 \mathrm{~W}$ & $9 \mathrm{~W}$ & $12 \mathrm{~W}$ \\
\hline Fixed end & Average & 0.0000031 & 0.0027 & 0.0132 & 0.0399 & 0.1039 \\
\hline Free end & Average & 0.0000005 & 0.0005 & 0.0025 & 0.0088 & 0.0340 \\
\hline
\end{tabular}




\section{Figures and Tables}

Used in Manuscript JMBBM-S-16-00249

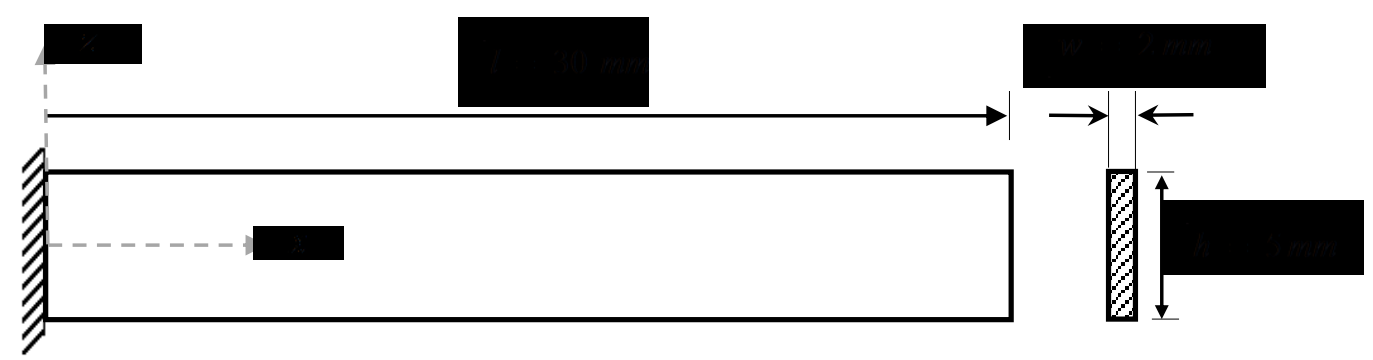

Fig. 1: Geometry of a degrading plate used in this study

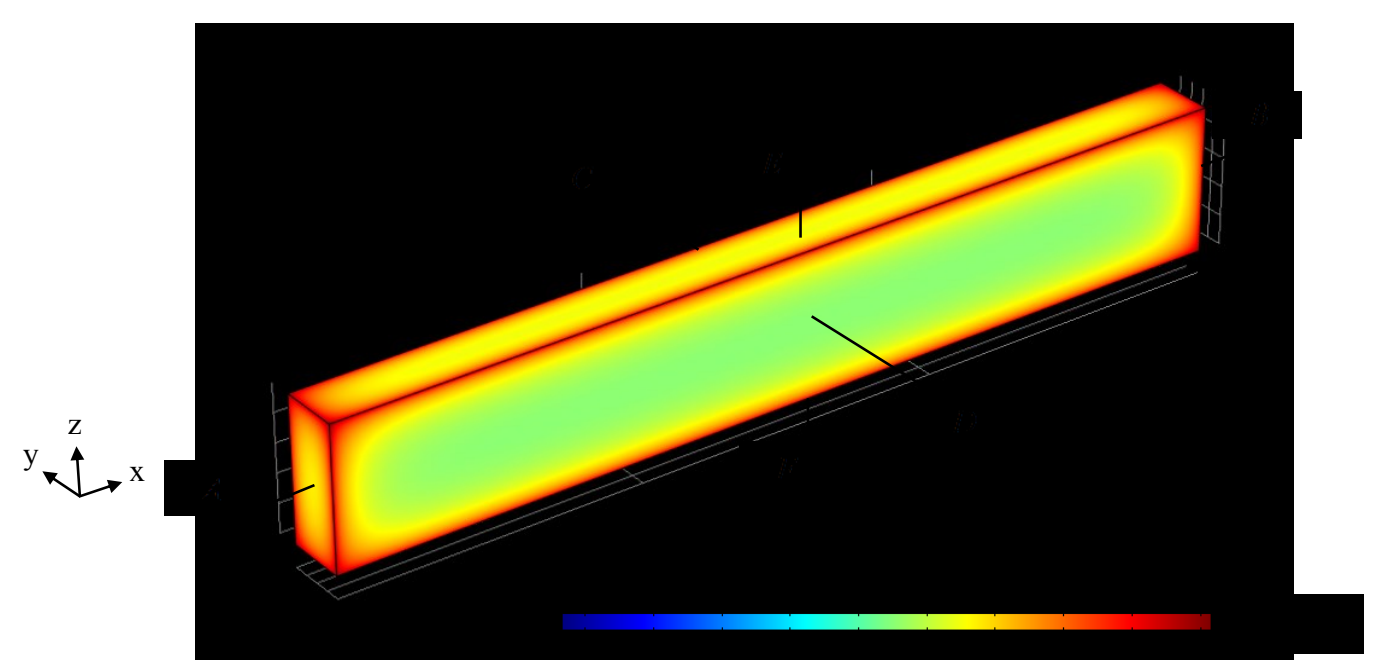

Fig. 2: Non-uniform degradation of a PLA/PGA plate at week 12 


\section{Young modulus of degrading PDLLA beam}
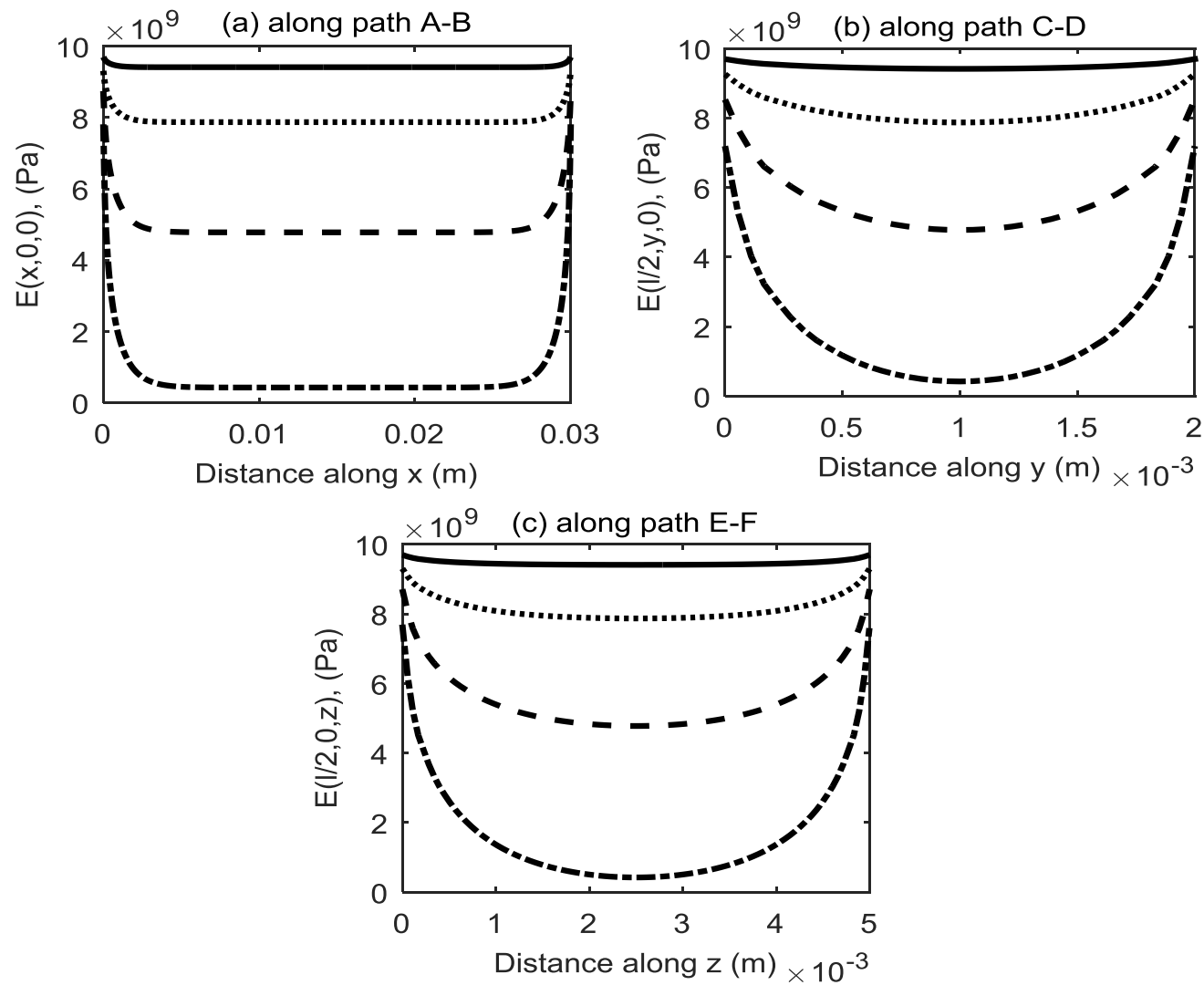

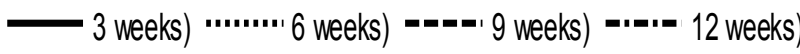

Fig. 3: Distributions of Young's modulus of the degrading plate along paths $A-B, C$ $D$ and $E-F$ (indicated in Fig. 2) at different degradation times

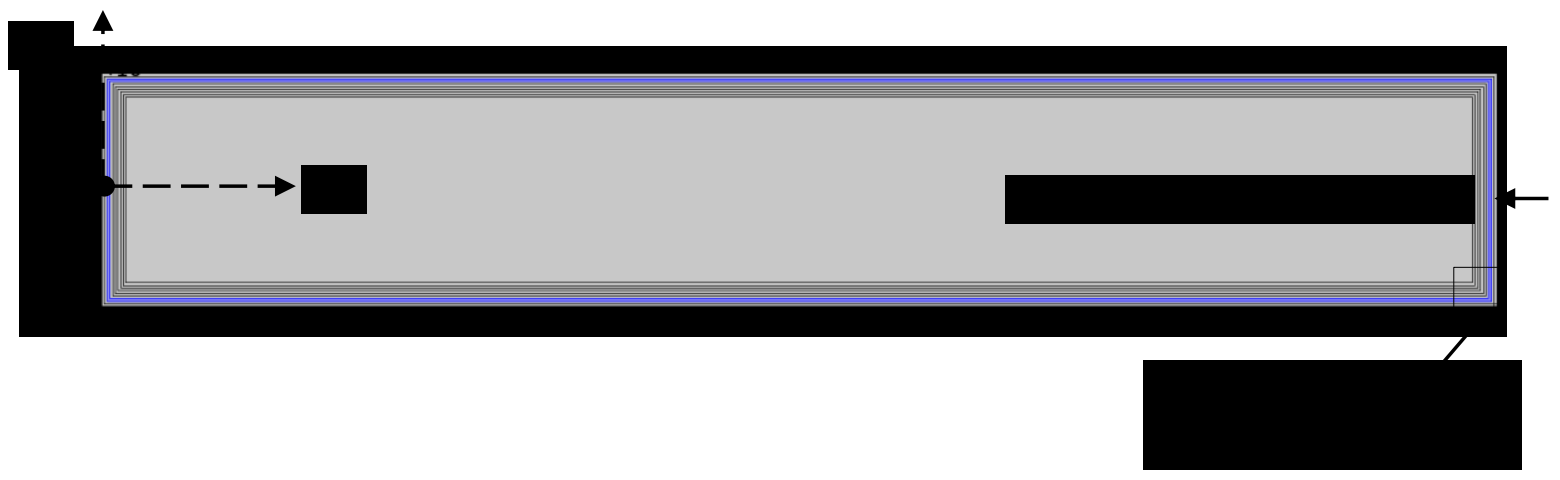

Fig. 4: The layered model of the plate used in the dynamic analysis 


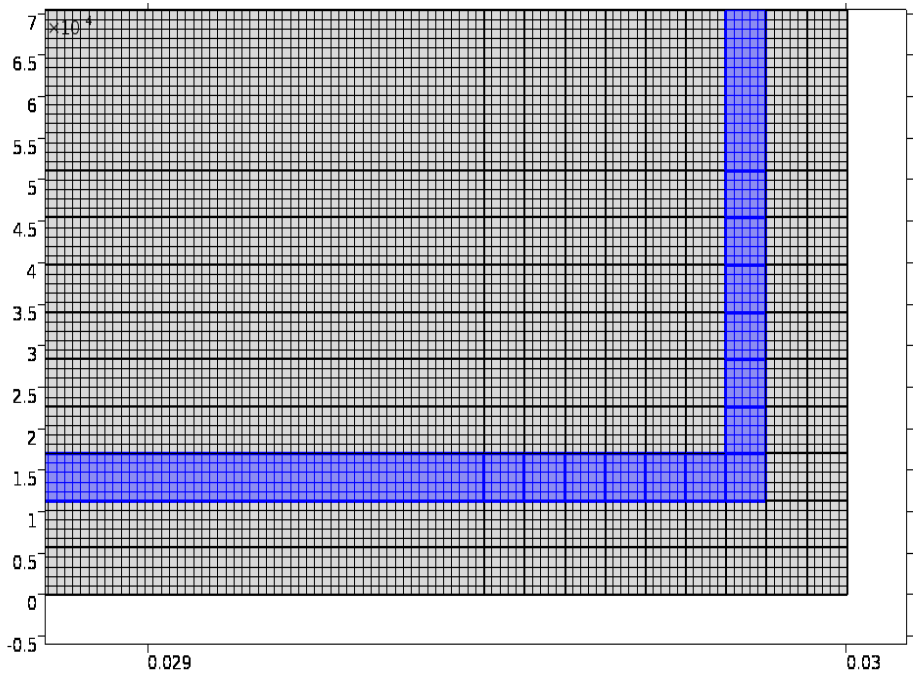

Fig. 5: Finite element mesh in a zoomed-in region showing the different layers

(a) $U^{(1)}$

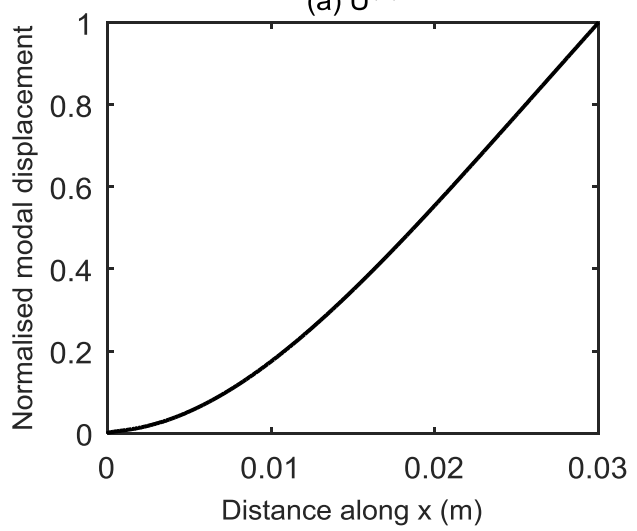

(c) $U^{(3)}$

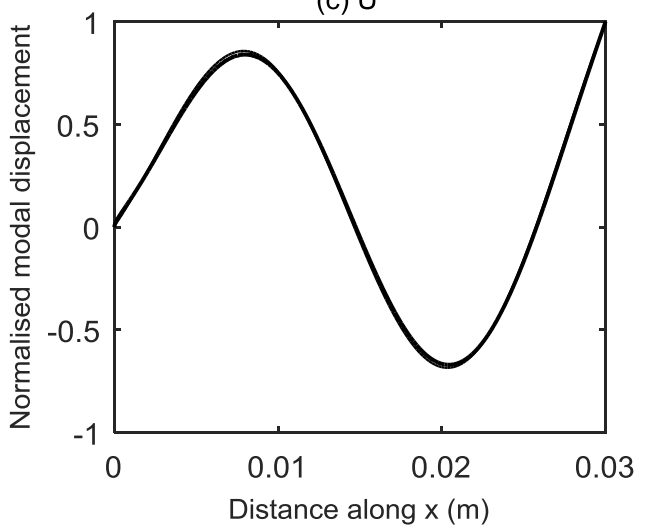

(b) $U^{(2)}$

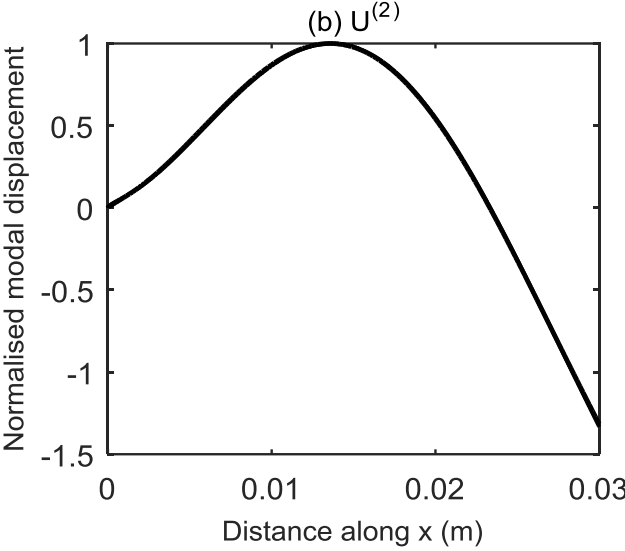

(d) $U^{(4)}$

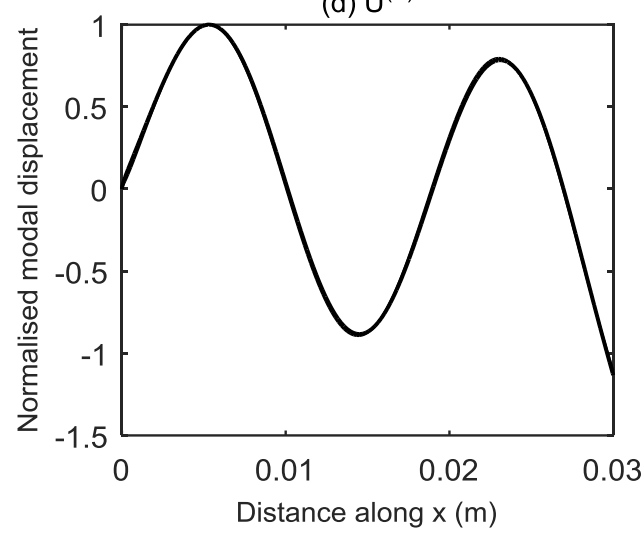

0 weeks, ---3 weeks, $-\cdot---6$ weeks,

9 weeks,

12 weeks

Fig. 6: The first four finite element (FE) simulated displacement mode shapes $U^{(n)}$ of the intact and degrading cantilever beam at different degradation times 

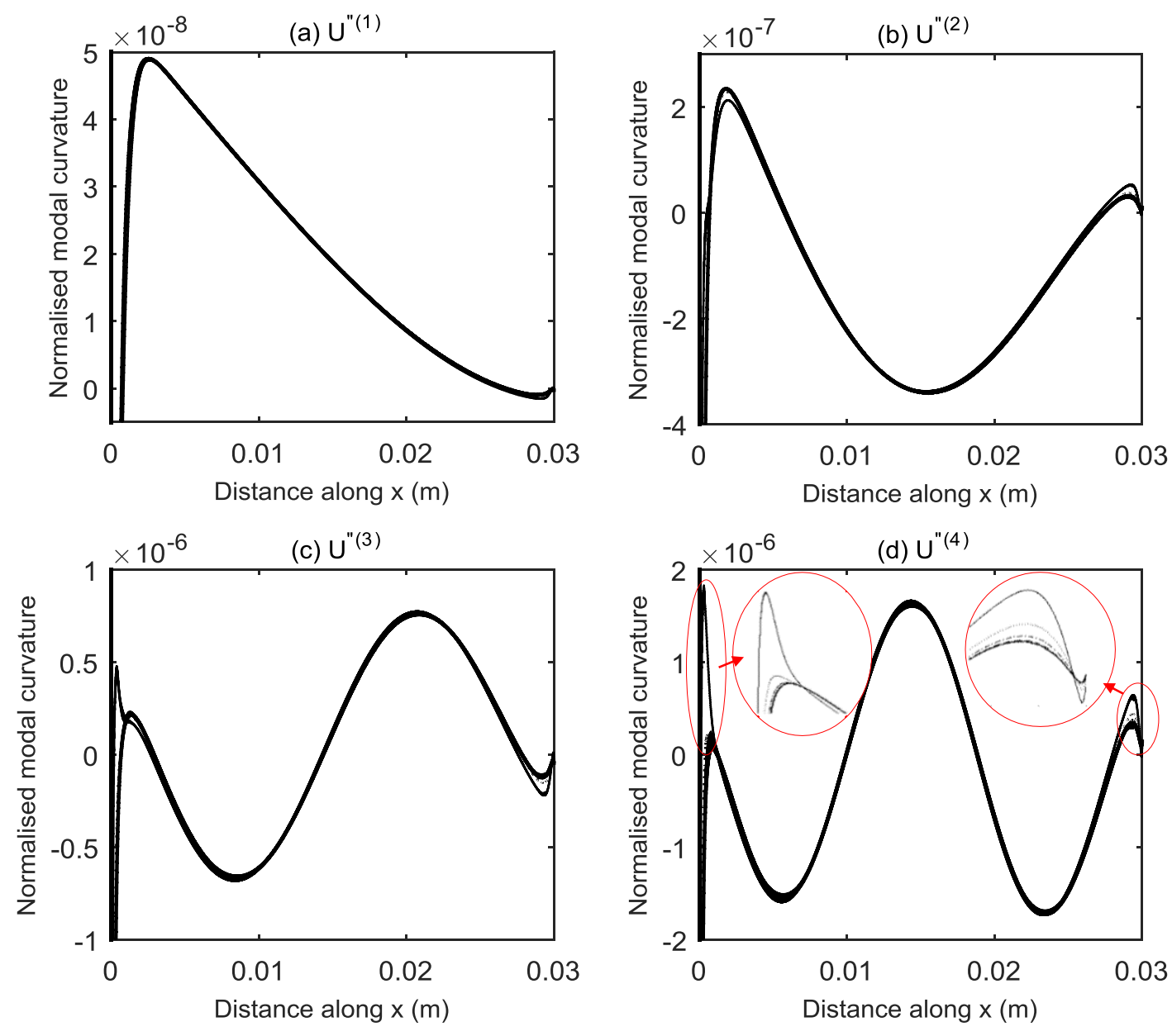

0 weeks, ---3 weeks, -----6 weeks

9 weeks,

12 weeks

Fig. 7: Curvatures of the first four displacement mode shapes, $U^{\prime \prime}(n)$, of the $2 D$ cantilever beam at different degradation times 

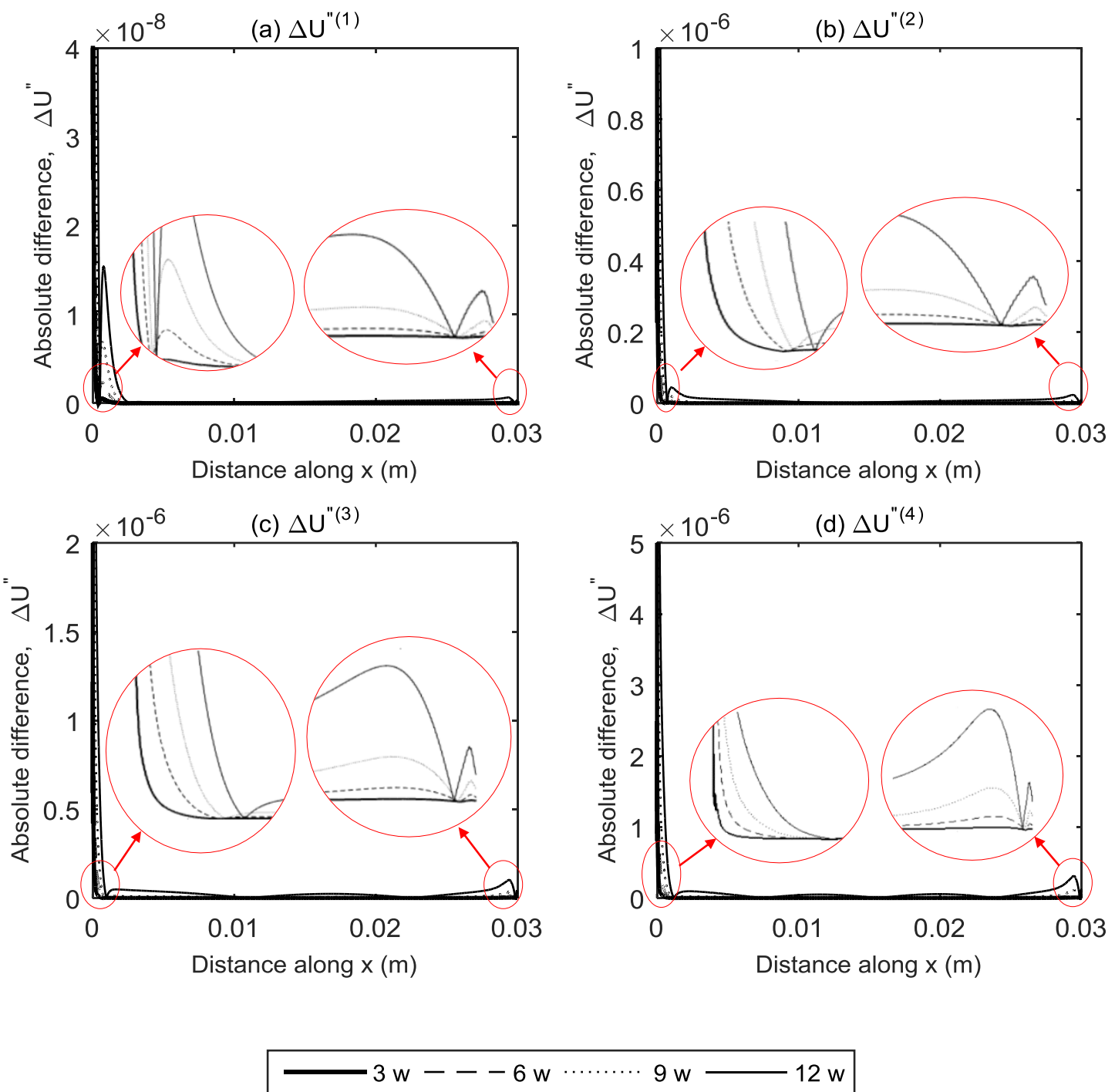

Fig. 8: Absolute difference between curvatures of the mode shapes for degrading and intact plates at different degradation times 


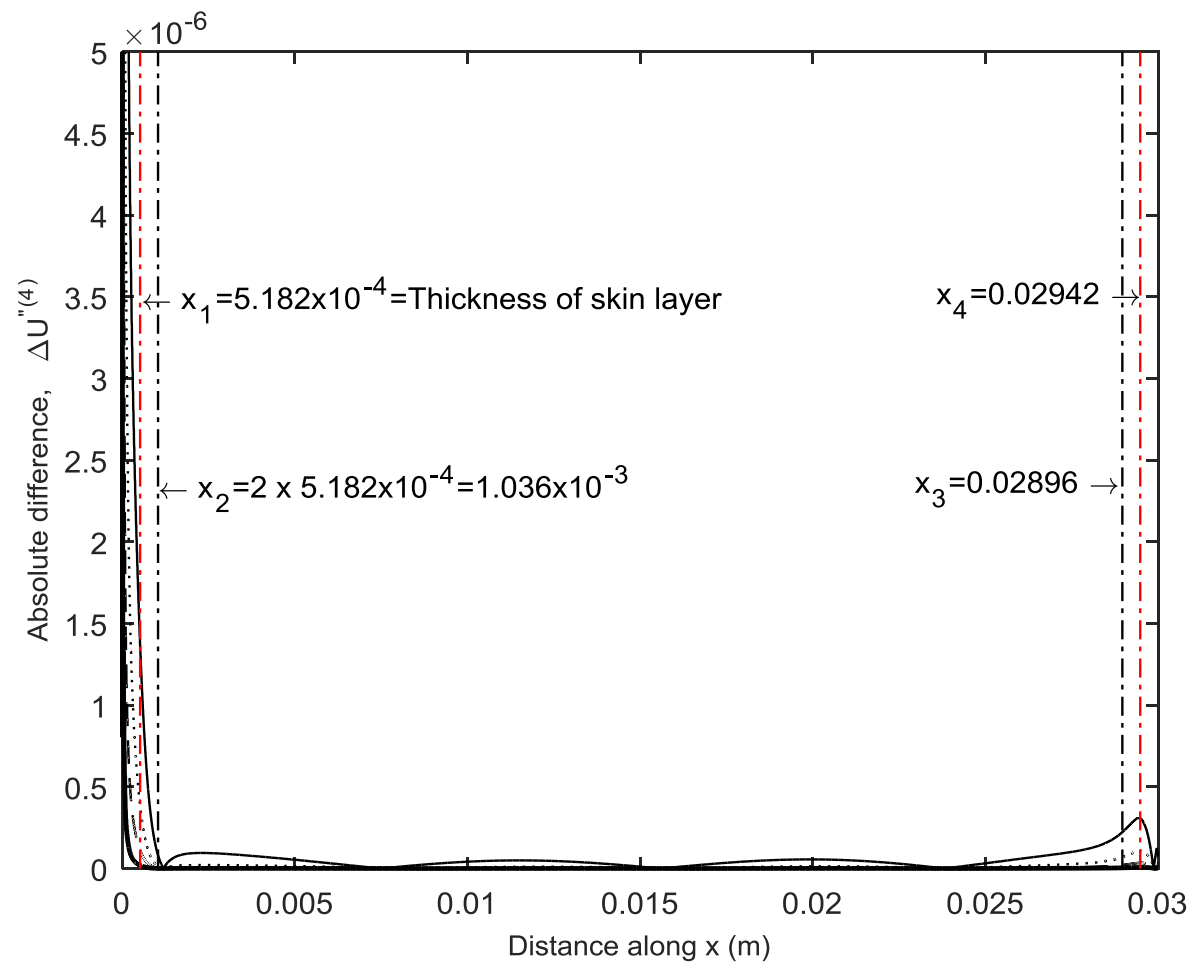

$3 \mathrm{w}---6 \mathrm{w} \cdots \cdots+12 \mathrm{w}$

Fig. 9: Absolute difference between the fourth curvature mode shapes of the degrading and intact beams (using 2D model)

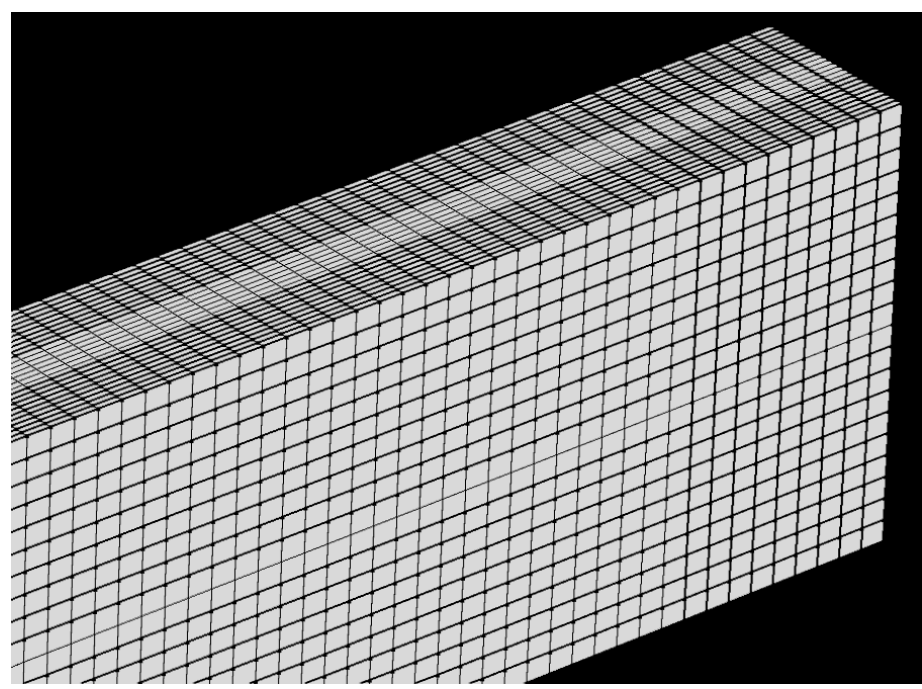

Fig 10. The 3D model of the degrading beam for mode shape analysis 


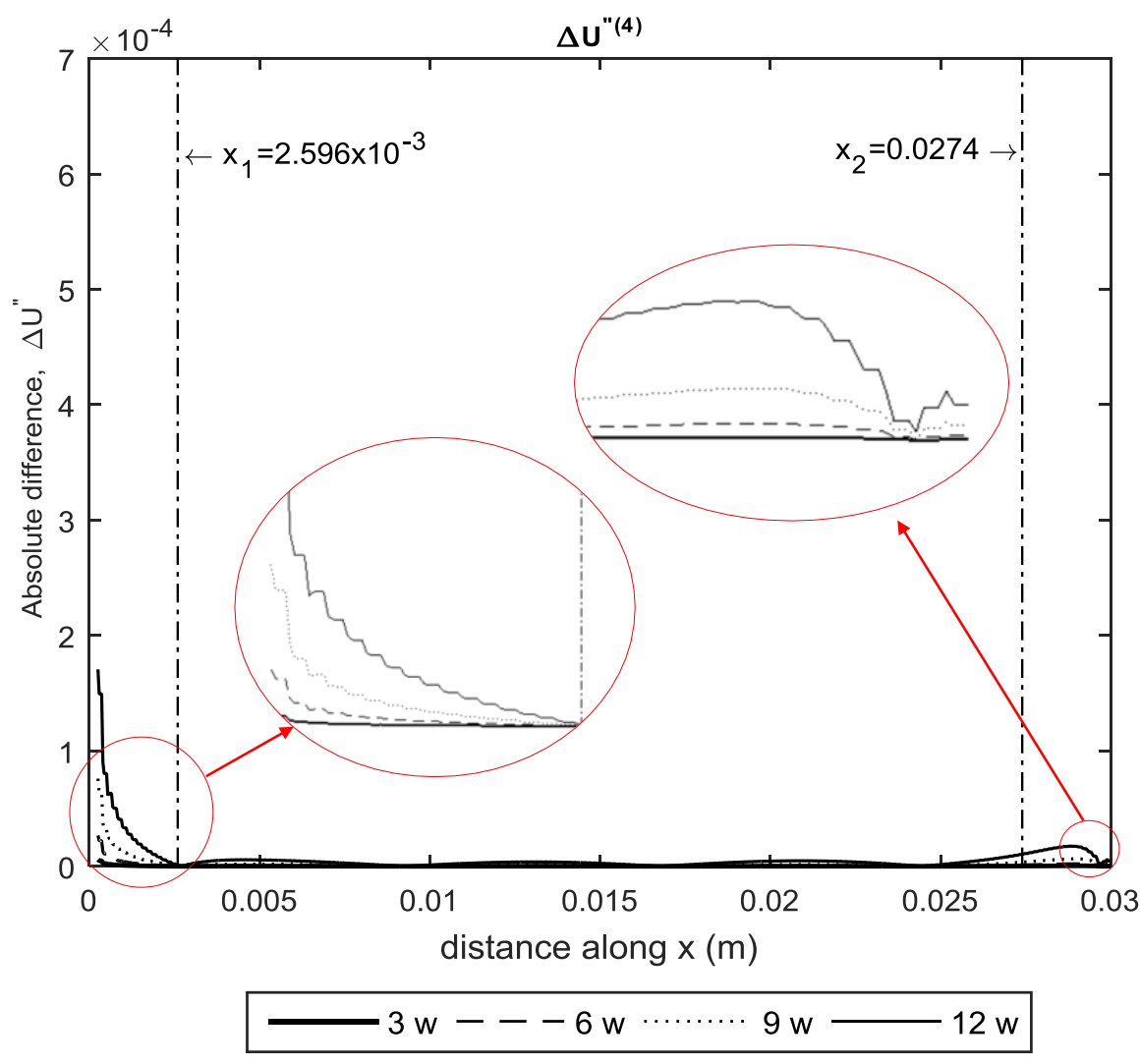

Fig 11. Absolute difference between the fourth curvature mode shapes of the degrading and intact beams (using $3 D$ model) 


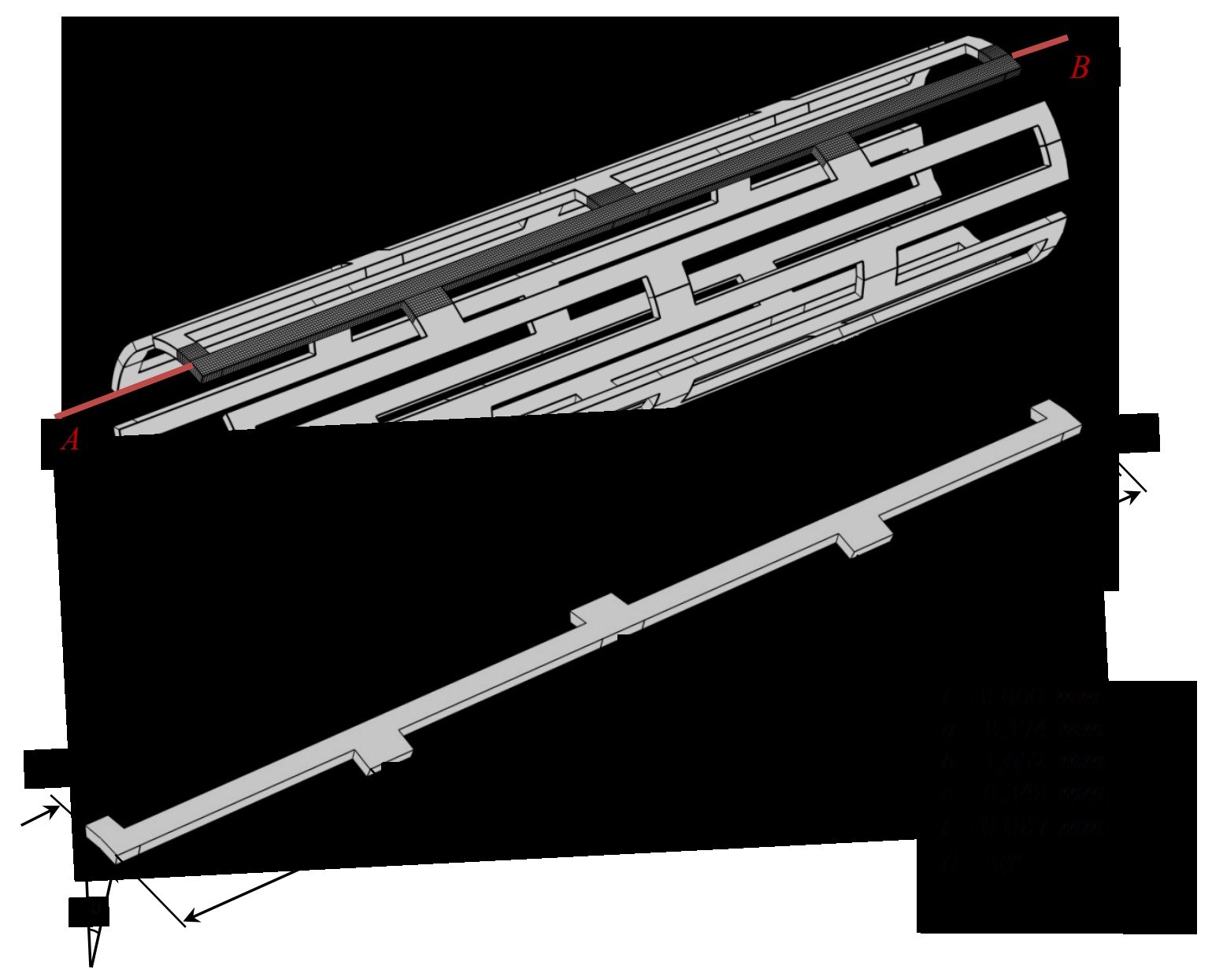

Fig 12 Geometry of a coronary stent and the part used in the dynamic study 


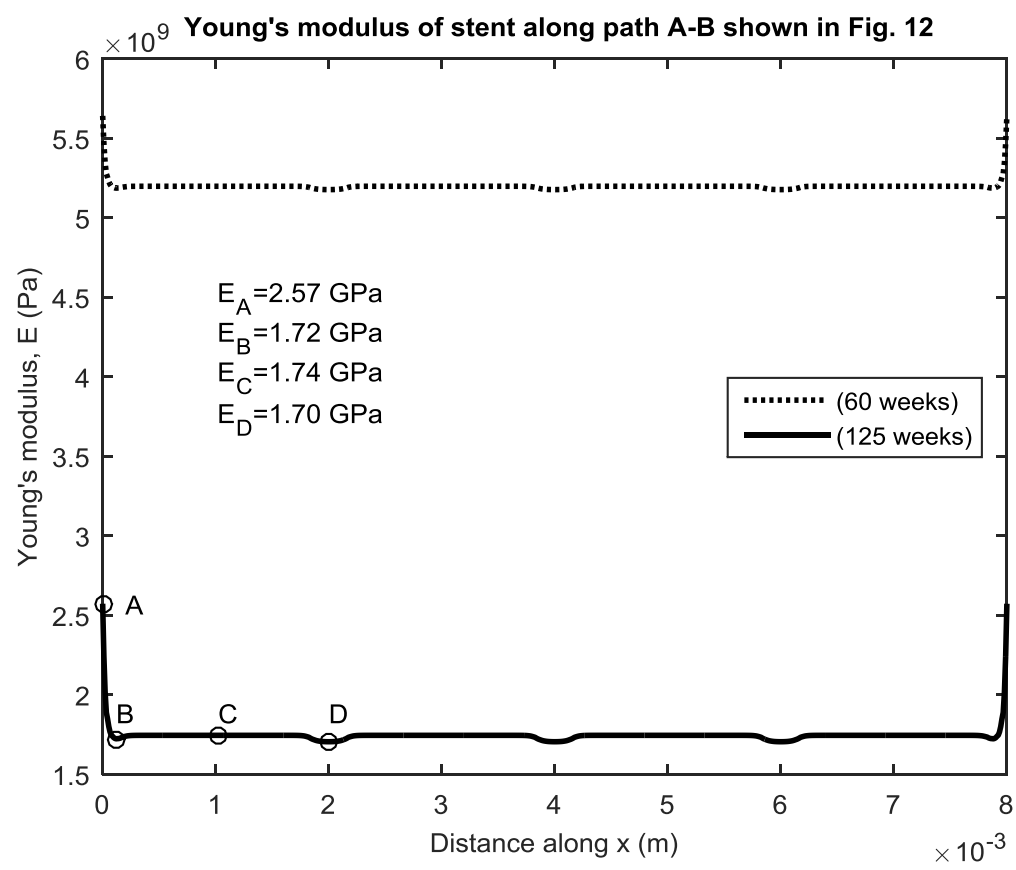

Fig 13 Distribution of Young's modulus in the stent along path A-B shown in Fig 11 after 60 and 125 weeks of degradation 

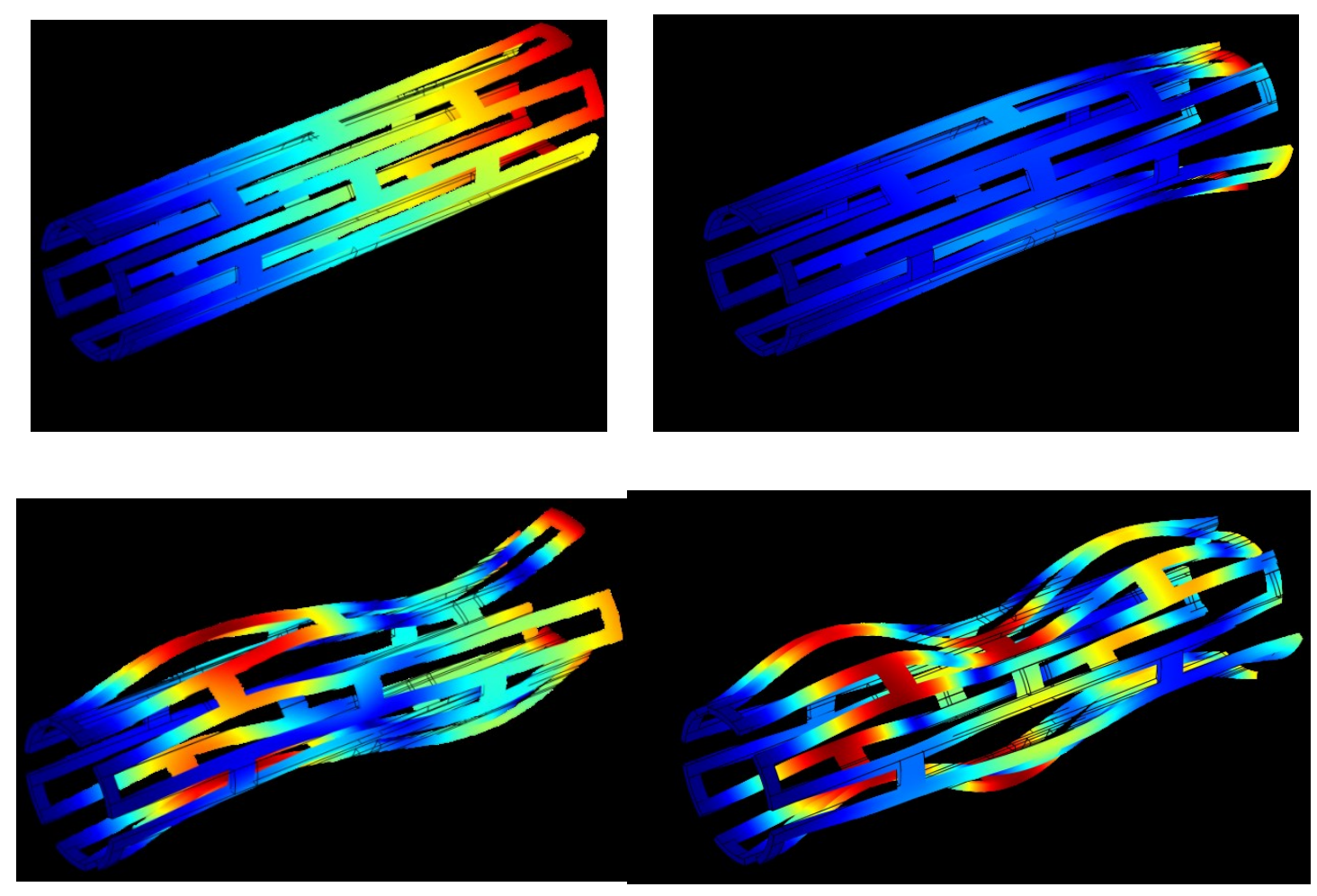

Fig 14. The first four mode shapes of the degrading stent after 125 weeks of degradation 
(a) 60 weeks

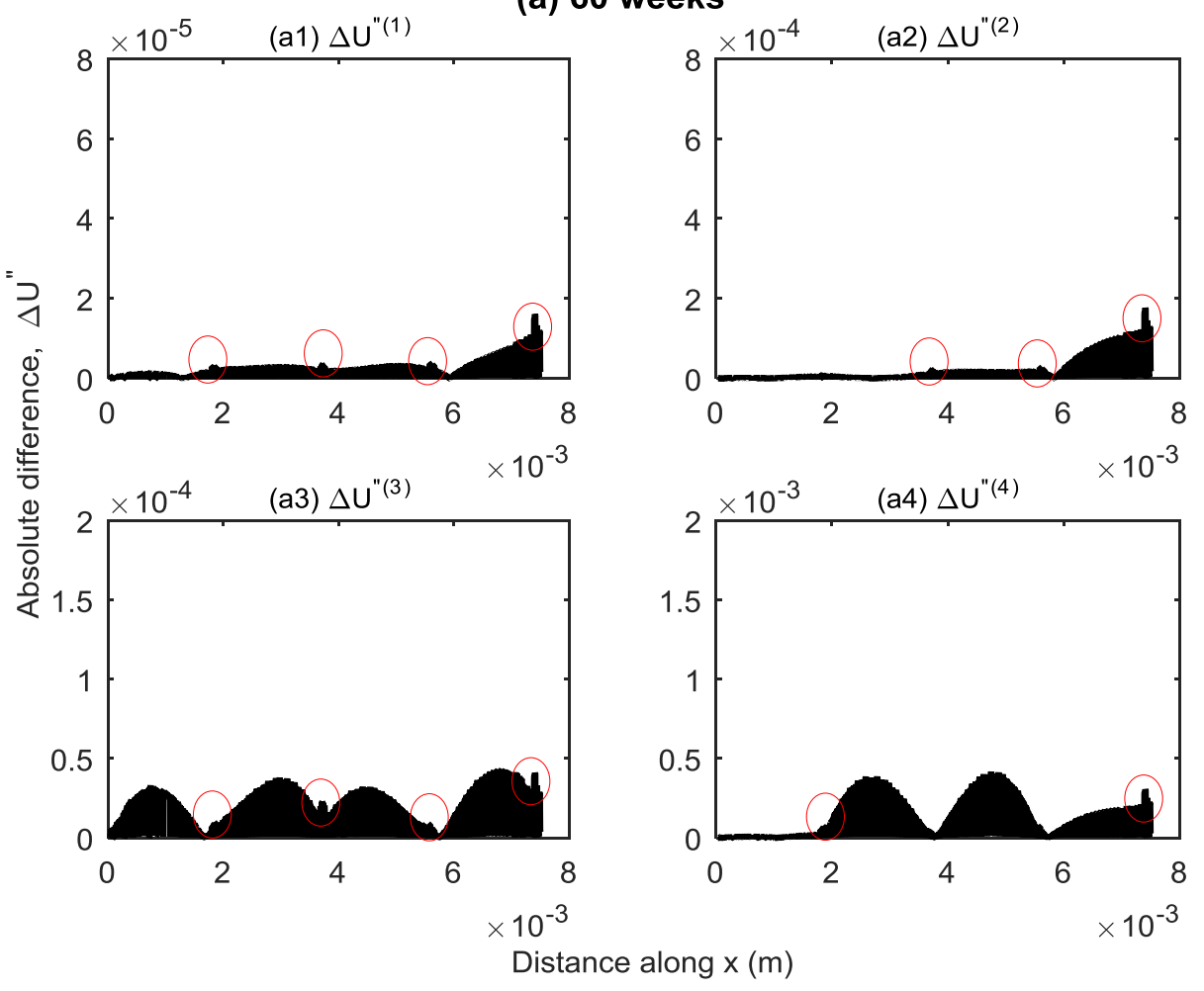

(b) 125 weeks

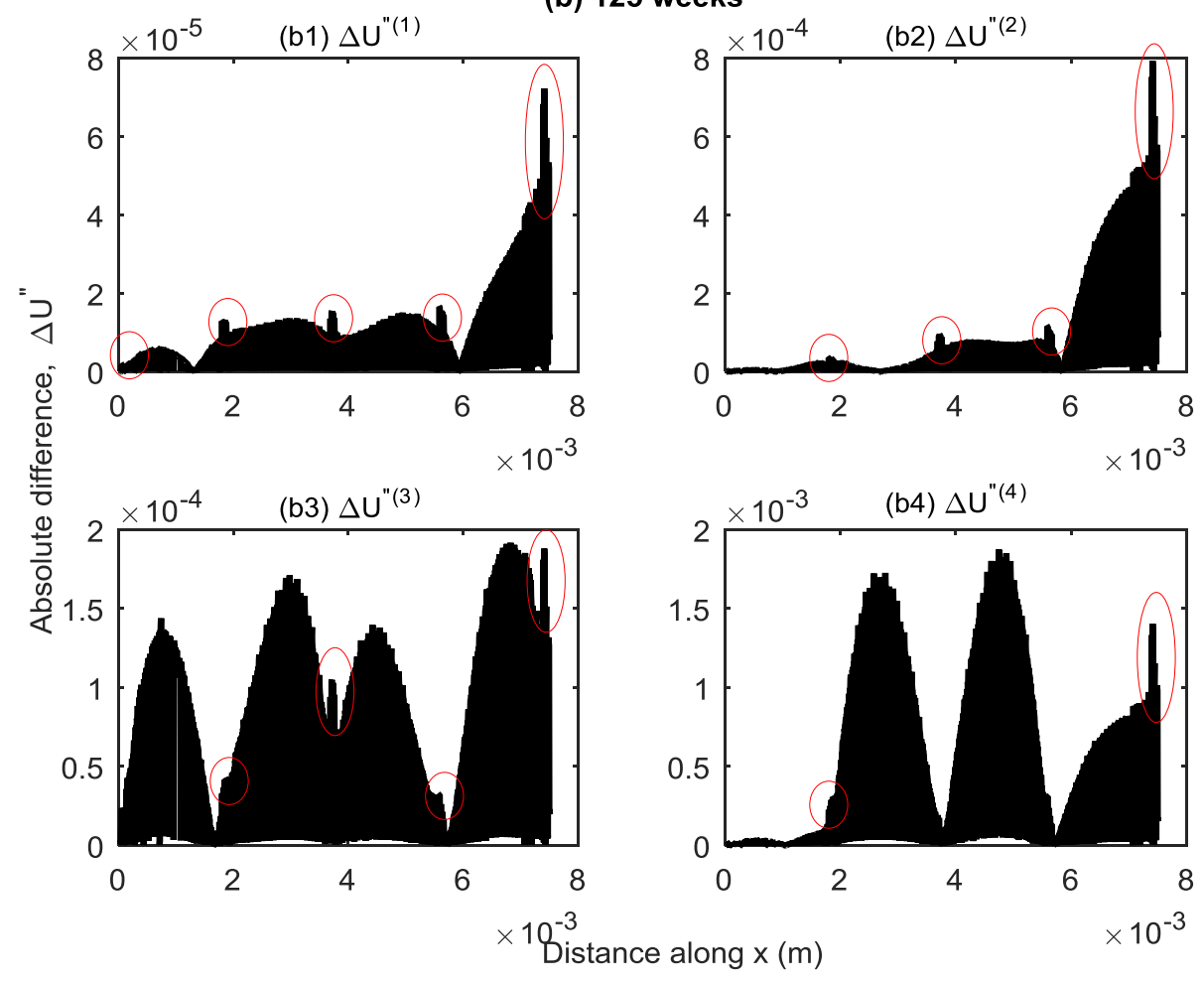

Fig 15: Absolute difference between curvatures of the four mode shapes for the intact and degrading stent after 60 (a) and (b) 125 weeks of degradation 